\title{
Improved emission properties of polymer photonic crystal lasers by introducing a phase-shift
}

\author{
Christiansen, Mads Brøkner; Buss, Thomas; Smith, Cameron; Kristensen, Anders
}

Published in:

Lasers and Electro-Optics (CLEO) and Quantum Electronics and Laser Science Conference (QELS)

Publication date:

2010

Document Version

Publisher's PDF, also known as Version of record

Link back to DTU Orbit

Citation (APA):

Christiansen, M. B., Buss, T., Smith, C., \& Kristensen, A. (2010). Improved emission properties of polymer photonic crystal lasers by introducing a phase-shift. In Lasers and Electro-Optics (CLEO) and Quantum Electronics and Laser Science Conference (QELS) (pp. 1-2). IEEE.

\section{General rights}

Copyright and moral rights for the publications made accessible in the public portal are retained by the authors and/or other copyright owners and it is a condition of accessing publications that users recognise and abide by the legal requirements associated with these rights.

- Users may download and print one copy of any publication from the public portal for the purpose of private study or research.

- You may not further distribute the material or use it for any profit-making activity or commercial gain

- You may freely distribute the URL identifying the publication in the public portal 


\title{
Improved Emission Properties of Polymer Photonic Crystal Lasers by Introducing a Phase-shift
}

\author{
Mads Brøkner Christiansen, Thomas Buß, Cameron L. C. Smith, and Anders Kristensen \\ DTU Nanotech, Department of Micro- and Nanotechnology \\ Technical University of Denmark \\ DK-2800 Kongens Lyngby, Denmark \\ mads.christiansen@nanotech.dtu.dk
}

\begin{abstract}
Introducing a phase-shift in nanoimprinted polymer dye lasers is shown to increase the probability of single mode lasing from 19\% to $99 \%$. Low-index lasers with only one longitudinal mode are thus superior to band-edge lasers.

C2010 Optical Society of America

OCIS codes: (140.2050) Dye Lasers; (140.0140) Lasers and laser optics; (050.5298) Photonic crystals

Additional key words: nanoimprint, combined nanoimprint and UV lithography.
\end{abstract}

In recent years a number of nanoimprinted polymer photonic crystal band-edge lasers have been demonstrated $[1,2,3]$. However, due to the low refractive index contrast in these lasers, the band gaps are not complete and the band edges are not separated very far in any crystal direction. This increases the chance of lasing at both band-edges, due to spatial hole-burning. We demonstrate that by introducing a $\lambda / 4$ phase-shift in rectangular lattice photonic crystal lasers, a single longitudinal mode at the Bragg frequency becomes favourable, and this improves the single mode properties of the lasers.

The lasers are defined in a thin film of photo-definable Ormocore hybrid polymer or SU-8, doped with the laser dye Pyrromethene 597. They are $375 \mathrm{~nm}$ thick slab waveguides with a rectangular lattice of $100 \mathrm{~nm}$ deep air holes imprinted into the surface, see Fig. 1(a). The short lattice constant (a) is $200 \mathrm{~nm}$, while the long lattice constant $(b)$ is $355 \mathrm{~nm}$. A compact frequency doubled Nd:YAG laser $(532 \mathrm{~nm}, 5 \mathrm{~ns}$ pulses) is used to pump the lasers from above the chip. The rectangular photonic crystal lattice provides both laser feedback and also dramatically increases the amount of pump light being absorbed [4].

The lasers are fabricated in parallel on a $10 \mathrm{~cm}$ diameter wafer by combined nanoimprint and photolithography (CNP) [5]. CNP relies on a UV transparent quartz nanoimprint stamp with an integrated metal shadow mask, Fig. 1(b). In the CNP process the photonic crystal is formed by mechanical deformation (imprinting) while the larger features are defined by UV exposure through the combined mask/mold.
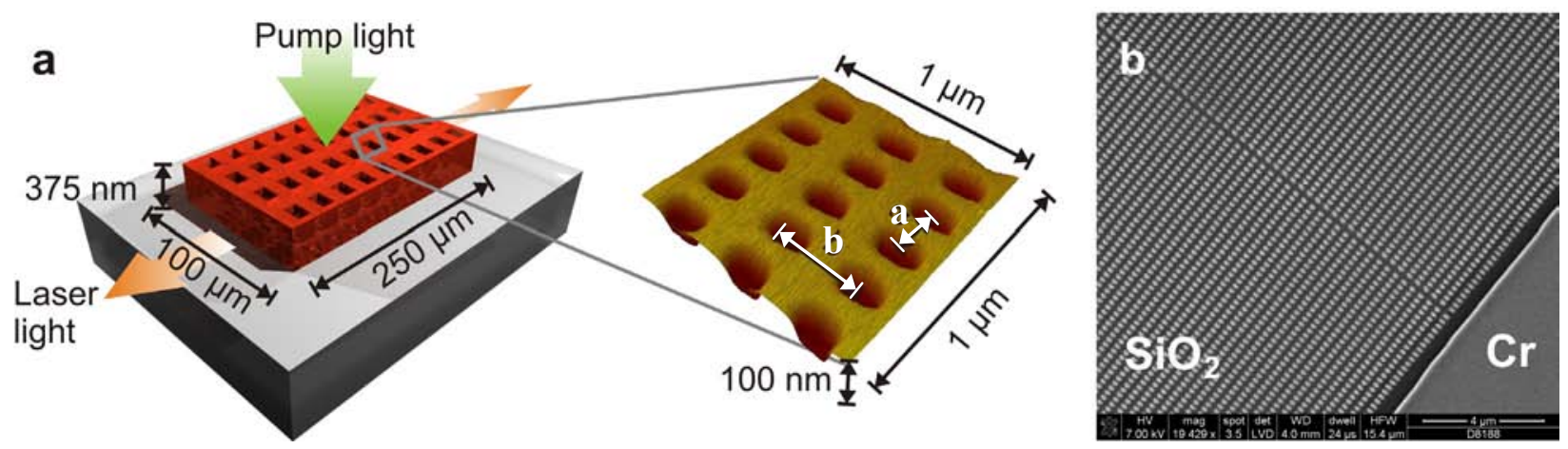

Figure 1: (a) Illustration of the polymer lasers, with an inset AFM image of the surface. (b) SEM image showing part of the stamp. The phaseshift, grating protrutions, and $\mathrm{Cr}$ shadow mask are seen.

Three wafers with 60 lasers where imprinted, two in Ormocore and one in SU-8. All lasers where nominally similar, except that half of them had a $\lambda / 4$ phase-shift in the center. The fabrication yield was $85 \%$ for the SU- 8 lasers and $58 \%$ for the Ormocore lasers. 63 of the 64 phase-shifted lasers were single mode, while this was only the case for 11 of the 58 unshifted lasers. A typical wafer map of laser properties is shown in Fig. 2, as are typical lasing spectra. 


\section{CThS4.pdf}

For the SU-8 lasers the lasing thresholds are $2.6( \pm 0.7) \mu \mathrm{J} / \mathrm{mm}^{2}$ and $3.3( \pm 1.3) \mu \mathrm{J} / \mathrm{mm}^{2}$ for the shifted and unshifted lasers, respectively. This is low compared to other nanoimprinted polymer lasers [1,2], which is attributed to the efficient resonant pumping scheme. The laser wavelength of the phase-shifted lasers is $614.5( \pm 0.9) \mathrm{nm}$.
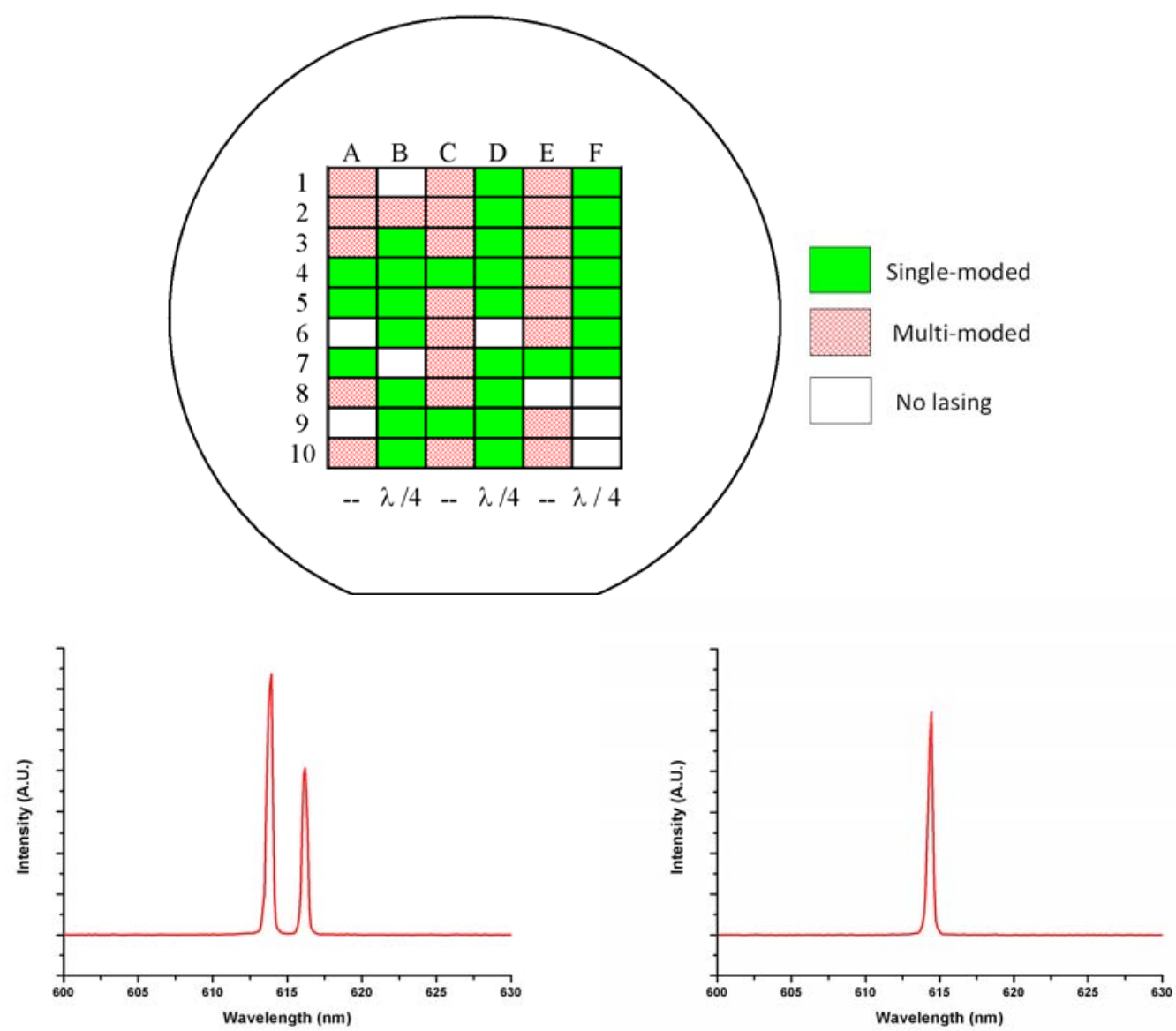

Figure 2: (Top) Distribution of single and multi mode lasers on a 4 inch wafer imprint. The phase-shifted lasers are in rows B, D, and F.

(Bottom left) Typical spectrum for an unshifted band-edge laser pumped at $8 \mu \mathrm{J} / \mathrm{mm}^{2}$ (Bottom right) Typical spectrum for a quarter wave shifted laser pumped at $8 \mu \mathrm{J} / \mathrm{mm}^{2}$.

The temperature stability of the lasers is $0.06 \mathrm{~nm} / \mathrm{K}$ and $0.042 \mathrm{~nm} / \mathrm{K}$ for the Ormocore and SU- 8 lasers, respectively. The organic laser dye is degraded during operation, giving a halflife of the lasers of 3700 pulses for the Ormocore lasers and 1090 for the SU-8 lasers.

CNP fabricated lasers are cheap to fabricate and very simple to use. They are thus well suited as tunable light sources or sensing elements $[3,6]$ in single use lab-on-a-chip systems. We have demonstrated that by introducing a phase-shift, the reproducibility of single mode laser properties is substantially improved.

[1] Y. Chen, Z. Li, Z. Zhang, D. Psaltis, and A. Scherer, "Nanoimprinted circular grating distributed feedback dye laser", Appl. Phys. Lett. 91(5), 051109 (2007).

[2] V. Reboud, N. Kehagias, P. Lovera, M. Zelsmann, C. Schuster, F. Reuther, G. Greutzner, G. Redmond, and C. M. Sotomayor Torres, "Fabrication of Defect-Free Nanoimprinted Photonic Crystals for Laser Applications", Jpn. J. Appl. Phys., 47(6), 5139 (2008).

[3] Felipe Bernal Arango, Mads Brøkner Christiansen, Morten Gersborg-Hansen, and Anders Kristensen. "Optofluidic tuning of photonic crystal band edge lasers". Appl. Phys. Lett., 91, 223503 (2007).

[4] Mads Brøkner Christiansen, Anders Kristensen, Sanshui Xiao, and Niels Asger Mortensen, "Photonic integration in k-space: Enhancing the performance of photonic crystal dye lasers", Appl. Phys. Lett. 93(23), 231101 (2008).

[5] Mads Brøkner Christiansen, Mikkel Schøler, and Anders Kristensen, "Integration of active and passive polymer optics", Optics Express 15(7), 3931-3939 (2007).

[6] Mads Brøkner Christiansen, Joanna Malgorzata Lopacinska, Mogens Havsteen Jakobsen, Niels Asger Mortensen, Martin Dufva, and Anders Kristensen. "Polymer Photonic Crystal Dye Lasers as Optofluidic Cell Sensors". Opt. Express, 17(4), 2722 (2009). 